\title{
Psychosocial roots of genocide: risk, prevention, and intervention
}

\author{
LINDA M. WOOLF and MICHAEL R. HULSIZER
}

Staub (1989), Rummel (1996), and others (e.g. Hirsch, 1995; Kressel, 1996; Stanton, 1998) have written extensively about the underlying root conditions and causes of genocide and mass violence. These theoretical models and the research related to genocide and mass violence can be integrated and augmented to create a risk analysis model aimed at the prevention of genocide. The spiraling risk for fomentation of enmity within a group and directed against those defined as "other" can be assessed by examining a myriad of factors underlying mass violence and genocide. Factors including group cultural history, situational factors, social psychological factors and context, and interpersonal factors, can be examined to provide an assessment of risk for movement along a path of mass violence with hallmarks including stigmatization, dehumanization, moral disengagement, moral exclusion, impunity, and bystander interactions. Risk assessment can then be applied to an analysis aimed at the selection of effective prevention strategies.

It is important to note that variations of this risk analysis model can be applied to mass violence in many forms and contexts. However, the dynamics shift depending on whether one is discussing forms of terrorism, democide, genocide, etc. Nonetheless, the fundamental features of the model, such as risk factors associated with group cultural history, the role of authoritarian leaders, and the manipulation of social psychological factors to propel a group down the path of mass violence remain the same. Additionally, steps aimed at the prevention of genocide are also applicable to other forms of mass violence.

It should be acknowledged that there is no general agreement as to a non-legal definition of genocide. For the purpose of this article, the definition outlined by Fein (1994a) will be used. Additionally, this essay will focus specifically on genocide, in particular on genocide as it occurs within nation-states against an identifiable target group. Although this model can be used to discuss other instances of genocide, such as the threat of genocide committed by a nation-state outside of its initial boundaries (e.g. the Ukrainian famine orchestrated by the Soviets), the dynamics shift. For example, self-interest comes to play a much larger role and need for manipulation of social psychological factors may be highly diminished if intrastate media is controlled. 


\section{Group cultural history}

Human beings do not exist nor are they raised in a vacuum. Rather, people develop and live within a variety of cultures with distinct histories. Our identity and our perceptions of the world are shaped by our culture. Indeed, our very sense of what is normative whether in relation to morality or interpersonal relationships is molded by our sociocultural context. So what are the key characteristics of a society that could be identified as a "culture of violence"?

In these cultures we find three common patterns: the use of aggression as a normative problem-solving skill; a conflict orientation grounded in an assumption of antipathy with a perceived threat orientation; and an ideology of supremacy grounded in a history of dehumanization including the long-term institutionalization of bias and lack of acceptance for cultural diversity. Each can exist on the broad cultural level within nation-states as well as within more localized cultures associated with smaller groups or organizations. In many societies, aggression and violence are so much a part of everyday life that they are often assumed to be the natural order of life. In fact, some might argue that violent forms of aggression are a natural part of human evolutionary development and thus somewhat unavoidable. However, this line is reasoning is faulty. From an evolutionary perspective, other factors such as the development of language, the ability to organize and cooperate for mutual survival, and the development of prosocial behavior likely played a more pivotal role in the survival of humanity than aggressive behavior (Turnbaugh et al., 2001). Certainly if we examine cultures and even groups within cultures today, we find a great deal of variation in the degree to which people accept aggression as a primary problem-solving skill. For example, Jehovah's Witnesses and Quakers value non-violent forms of conflict resolution and tend to be highly pacifistic. Conversely, the major genocides of the twentieth century were all committed by or within states with a history of aggressive conflict and war (Staub, 1989). Cultures with a history of aggression and particularly those that culturally glorify violence (e.g. military parades, heroic violent media) are at great risk for perpetuating many forms of violence.

Aggression and prejudice researchers have demonstrated a strong relationship between perceived threat and prejudicial or aggressive behavior (Bobo and Hutchings, 1996; Leonard and Taylor, 1981). Indeed, this relationship is at the core of Blumer's (1958) classic group-position theory. Research has further established that individuals with a hostile attributional bias or perceived threat orientation are more prone to perceive aggressive intent in other's actions (Dodge et al., 1990). The relationship between aggressive behavior and perceived threat can also be extended to nations. In the absence of good intelligence or the free exchange of diplomatic information, states with a perceived threat orientation may assume that another group or nation presents a risk, they assume antipathy, and therefore, prepare for or initiate military conflict. For many decades, the former Soviet Union and the United States held each other at bay through the proliferation of weapons of mass destruction. The aforementioned military build-up was in response to an initial perceived threat, which then became a self-fulfilling 
prophecy. What began as differences in political ideology and concern regarding governmental encroachment quickly evolved into the very substantial risk of mutual annihilation through the use of nuclear weapons and thus served to reify all previous beliefs of threat. Only history will tell whether the 20032004 US military action in Iraq was in response to the existence of weapons of mass destruction or the result of a perceived but largely non-existent threat. It is important to note that perceived threat and accompanying aggression may evolve into long-standing conflict or what Staub (1989, pp 250-251) refers to as an "ideology of antagonism." In such a culture, individual identities are in part shaped by perceptions of themselves in conflict with the "other." Unfortunately, a key component accompanying a culture of violence characterized by a perceived threat orientation is the susceptibility of those within the culture to psychosocial manipulation by the elite. Playing on a majority population's fears and anxieties, leaders and other elite may work to influence perceptions for the promotion of violence. Thus, for example, citizens in Nazi Germany were warned about the growing tumor within the "body of Germany" that must be excised and films such as The Eternal Jew drew parallels between rats, a spreading plague, and Jews. Armenians in the Ottoman Empire were portrayed as an internal military threat working in tandem with invading Russian-Armenian forces (Adalian, 1997). A return to the ancient traditions of the empire of Angkor was perceived to be threatened by "westernized" Cambodians drawing on historic class differences between rural and urban Cambodians (Kiernan, 1997). Tutsis in Rwanda became identified and targeted as a dangerous invading force despite shared historical roots in the region (Mamdani, 2001). It is important to note that while it is easiest to draw on existing stereotypes and prejudices, these biases may have lain dormant for years. Thus, it is not uncommon when reading the literature of survivors of the Holocaust, the genocide in Bosnia, as well as other atrocities that neighbors who previously related well suddenly turned on them with seemingly new found hatred.

Cultures vary in the degree to which they are characterized by diversity as well as the degree to which they are open to and tolerant of such diversity. Pluralism alone does not decrease the likelihood of violence against the other. Rather violence appears to be related to the degree to which individuals, groups, and nations accept an ideology of supremacy. For example, researchers have found that individuals with a high social dominance orientation (SDO) are more prone to endorse anti-Black racism and were more supportive of sexism, nationalism, and cultural elitism (Pratto et al., 1994). Furthermore, those individuals high in SDO were consistently opposed to gay and lesbian rights, women's rights, and ameliorative racial policies. In addition, researchers have found that artificially inflated self-esteem, which would be one consequence of adopting an ideology of supremacy, is highly predictive of aggressive behavior in the event such egoism is threatened (Baumeister et al., 1996). Given that there is a well documented link between violence and an ideology of supremacy among individuals, it stands to reason that this relationship would also extend to groups and nations that view themselves as innately and fundamentally superior. For example, the 
Nazis viewed themselves and all people of "Aryan race" as fundamentally superior to the "sub-races" (that is, Slavs, Jews and Gypsies) who were viewed as defiling the body of Germany (i.e. perceived threat). The Hutu leaders and elite declared Hutus superior to the Tutsis (who were referred to as inyenzi or cockroaches) during the 1994 Rwandan genocide. One of the primary differences between patriotism and nationalism is that the latter holds at its core ethnocentric bias and belief in national superiority. It is also one of the reasons that genocides committed by collectivist cultures are particularly brutal towards those perceived as outsiders (e.g. the Nanking Massacre and other atrocities committed against the Chinese by the Japanese during World War II).

The ideology of supremacy within a culture is grounded in a history of dehumanizing the "other" and with the concomitant institutionalization of bias against the targeted group or groups. History teaches that those groups which have traditionally been marginalized but who now have attained a certain measure of success and assimilation within the broader culture are most at risk during times of crises. Thus, it comes as no surprise that Jews, Armenians, and Tutsis were all primary targets for genocide in their respective cultures as opposed to smaller, more marginalized, populations. This is not to say that other minority groups are not targeted. However, their inclusion as a target of persecution and enmity depends on a number of additional factors such as a history of marginalization and the authoritarian nature of the government. For example, Roma and Sinti were also targeted by the Nazis for genocide. During the Cambodian genocide, the Khmer Rouge also targeted the Vietnamese as "hereditary enemies" of the Cambodian "race" (Kiernan, 1997).

Clearly, all of the aforementioned group cultural history variables interact to facilitate the potential for mass violence. While cultures cannot change their histories, they can change their perception of such histories and work to undo the institutionalization of a perceived threat orientation, an ideology of supremacy, and the use of aggression as a primary means of problem-solving.

\section{Situational factors}

While cultures may carry the seeds for hate and violence within, other factors are needed to stimulate aggressive actions and the growth of enmity. Thus, one must look to the current situation in which a culture and its members exist to find the stimulus behind such growth. Various factors can be included in this discussion, but the two primary issues are destabilizing crises and authoritarian leaders or government.

\section{Destabilizing crisis}

Some researchers argue that difficult life conditions increase the likelihood of genocide (Staub, 1989). However, this approach may be overly simplistic. Many groups (particularly marginalized groups) live in harsh conditions daily, ranging from poverty to continuous threatened survival, without 
committing organized acts of mass violence. History suggests it may be more accurate to focus instead on crisis situations, particularly conditions that destabilize the region.

Crisis can be very unsettling and disorienting for individuals and may result in loss of group pride, an escalation of fear, frustration of needs and wants, confusion regarding personal identity, and an increase in prejudice (Staub, 1989). The classic research of Miller and Bugelski (1948) demonstrated that adolescents in a summer camp, deprived of an evening at the movies, displayed a sharp increase in prejudice directed toward groups with whom they had no contact. In a more recent study, researchers manipulated the level of embarrassment participants felt by leading them to believe that they were responsible for knocking over a stack of computer cards (Meindl and Lerner, 1984). The results revealed that participants who were embarrassed exhibited more hostility towards out-group members.

In addition, during times of crises, many individuals are drawn to religious groups, political groups, cults, hate groups, and so on. Organizations such as these can provide a framework for security, provide a sense of belonging and identity, and restore balance to someone in time of need. In the film Hate Groups USA (1998), an interviewee states that he joined a white supremacist group while in prison simply because, on his birthday, he received a card from every member of the group. Unfortunately, many of these groups may have at their base a fundamentally destructive ideology which gives little incentive for providing members with non-violent problem-solving strategies and may instead provide justification for violent behavior.

Those crises that destabilize the region, in other words, situations that result in unanticipated difficult life conditions in populations unaccustomed to such difficulty, present the greatest threat for the emergence of mass violence and genocide. Indeed, the major intrastate genocides of the twentieth century all included destabilizing crises that provided rich soil for destructive cultural change. Economic crises, political crises (particularly the fall of an early attempt at democracy), or the effects of war were present in the immediate years prior to or concomitant with the following genocides: the genocide of the Armenians by the Young Turks, the Holocaust at the hands of the Nazis, the genocide in Bangladesh, the Cambodian genocide, "ethnic cleansing" within various regions of the former Yugoslavia, and the Rwandan genocide. Other factors that may destabilize a region include concerns over sovereignty of land and resources, third party dominance and interference (for example, colonization), disparate allocation of and access to power and resources, scarcity of resources, environmental crises, attack on national or group identity, and threat of conflict or war (Landis and Boucher, 1987). All of these factors increase the likelihood of intra- and intergroup animosity and violence. When numerous forms of crisis cluster together (e.g. economic and political crises in the Weimar Republic) and/or the effects of a previous crisis linger and remain unresolved (e.g. the effects of colonization and post-colonization in Burundi and Rwanda), the potential for violent action further magnifies. 


\section{Authoritarian leaders}

While crisis and the presence of destabilizing factors play a major role in the initiation of hatred and mass violence, a second major situational factor needs to be included: leaders. According to Rummel (1996), it is not coincidental that only non-democratic nations in the twentieth century committed genocide or initiated a war. One key characteristic of genocidal states is the presence of a totalitarian ruler and an authoritarian form of government. The influence of leaders can be used to transform or magnify existing components within a society into what Staub (1989, p 19) refers to as a "monolithic culture." Such cultures often have a strong history of obedience to the state and authoritarian rulers as well as a lack of tolerance for diversity. Each of the aforementioned major genocides occurred in a crisis period following a failed attempt at democracy with a resulting rise to power of a totalitarian form of government. It should be noted, however, that while democracies may not have been directly responsible for genocide, there is ample evidence to demonstrate that democratic nations have played a complicit role during mass murder and violence. For example, the US supported through aid, intelligence, and/or training the violent overthrow of governments and mass murder in various regions of South and Central America (Staub, 2003).

Authoritarian leaders play a significant role in moving a culture down a path of mass violence. Often such efforts are designed to solidify and maintain power by eliminating opposition, the centralization of power, the promotion of economic self-interest, the creation of a destructive infrastructure and culture, and to reify destructive ideologies. The elimination of political opponents through the use of expulsion, imprisonment, or death has been commonly employed by totalitarian leaders. Milosevic conspired to have moderates ousted from the Central Committee, moderate Hutus were among the first killed during the Rwandan genocide, and the Night of the Long Knives resulted in the death of Ernst Roehm and others who represented a potential threat to Hitler. Such efforts not only significantly decrease oppositional voices but also create a climate that facilitates groupthink and the polarization of destructive ideology. In time, power becomes highly centralized and can be extended to non-state organizations such as the media.

Leaders within totalitarian states are also highly motivated by self-interest. While the population of Rwanda suffered from severe economic crisis, the Hutu leadership became wealthier and wealthier. Stolen art, money funneled into Swiss bank accounts, and other financial benefits accrued by the Nazis as a function of war and genocide have been well documented. Such self-interest can be extended to the broader majority population building further support for the authoritarian and genocidal state. Thus, economically, many Germans benefited from the looting of Jewish assets and Nazi incursion into neighboring countries.

Genocide and the processes of mass murder do not occur spontaneously but rather must be organized and orchestrated. Thus, authoritarian leaders work to maintain their roles through the creation of a destructive culture and infrastructure. Early on, authoritarian leaders may work to develop a military or quasi-military structure. Uniforms and clearly identifiable proscribed rules for behavior can 
facilitate the willingness of individuals to commit acts of state ordered violence by enhancing deindividuation, conformity, and diffusion of responsibility. In addition, a culture of destruction can be further facilitated by the careful use of language. According to Lifton (1989), the development of jargon associated solely with the group facilitates group membership and identification, conformity, and isolationism. Furthermore, the use of euphemistic language can aid in escalation of violence and moral exclusion. For example, it was much easier to state that Jews were being transported to the east than to state that they were being transported to death camps.

Finally, authoritarian leaders are able to promote destructive ideologies within their own cultures. Such ideologies often are presented as moral, highly idealistic, and for the greater good. Thus, while leaders may or may not necessarily believe their own espoused ideologies, they are able to create fanatic followers. Leadership, according to Staub (1989, p 23), "is a transactional process, a relationship between group and leader." Leaders will be able to respond to the needs and abilities of their followers and manipulate the context for their own success. Thus, Hitler and other Nazi leaders were able to use the growing popularity of the eugenics movement in Europe and North America to begin their campaign of racial hygiene. Communist ideals and visions of the lost empire of Angkor focused the efforts of the Khmer Rouge. Nationalistic dreams and Serbian solidarity provided the framework for destructive actions in the former Yugoslavia.

So what personality characteristics do genocidal leaders such as Hitler, Pol Pot, and Milosevic have that allow them to effectively lead their respective nations into committing mass violence? Some of the variables that appear to be consistently, albeit moderately, correlated with leadership success include (in no particular order): charisma, a desire for power and dominance, self-confidence, selfdirection, morality (and on the flip side, immorality), and intelligence (Bass and Stogdill, 1990; Chemers and Ayman, 1993; Hollander, 1985; Simonton, 1984). Unfortunately, there is not a well established body of research examining the characteristics associated with genocidal leaders, and the research that does exist is somewhat anecdotal and retrospective in nature. Additionally, it is important to note that although there might be superficial similarities among genocidal leaders, these correlations may not in fact be very meaningful. For example, Simonton (1987) collected information on the personal attributes of US presidents and found that only three characteristics, as rated by historians, predicted effectiveness in office: height, family size, and the number of books published prior to taking office. While these characteristics may be predictive, they are not overly informative as to what makes for an effective leader. Consequently, caution needs to be employed when examining unsystematic research on the personality characteristics of genocidal leaders.

Nations and cultures are deeply impacted by their leaders and ruling structure. Leaders who demand unconditional belief and support are in a position to manipulate not only the information received by their followers, but whether the culture functions to promote tolerance and constructive action or hatred and destructive violence. Additionally, leaders and the ruling elite are often highly motivated 
based on self-interest. When this self-interest parallels that of the dominant population, and aggression is the most risk-free means to attain the resources desired (e.g. power, land, and other economic incentives), then the potential for mass violence, including genocide, is enhanced.

Historically, countless indigenous populations have been faced with ethnocide and genocide due to desire for the resources they possessed. Additionally, those in positions of power are in a unique position to manipulate a host of social psychological factors that may then play a role in the development of mass violence and genocide.

\section{Social psychological factors}

One of the most powerful tools available to a leader is the ability to manipulate how the population thinks about, influences, and relates to each other. Therefore, the identification of the social psychological factors most amendable to distortion and manipulation is critical to developing an understanding of the antecedents that shape the emergence of genocide. The following discussion introduces relevant social psychological theory and phenomena and then examines the means by which these factors can be manipulated by genocidal leaders.

\section{Social cognition}

The manner by which individuals think about themselves and those around them can influence the likelihood of mass violence and genocide. According to Tajfel and Turner (1986), we tend to divide up the world into "us" and "them," or in-groups and out-groups. Additionally, the in-group we identify with is an important component in our social identity. It is important to us to belong to groups that are held in high esteem so that our social identity is seen in a positive light. Consequently, people often go to great lengths to enhance their social identity by ensuring their in-group is highly valued and distinct from other groups-a phenomenon referred to as in-group bias. One potential consequence of trying to achieve and maintain a high social identity is out-group-directed prejudice, discrimination, and in some cases, violence. However, this behavior is by no means automatic. Negative consequences of the in-group bias only tend to occur when people couple an extremely positive view of themselves, and by extension their in-group, with a very negative view of their out-groups (Brewer, 1979). Much of Nazi propaganda was aimed at creating just such a division with films such as The Triumph of the Will highlighting a strong, happy, proud Germanic race while films such as The Eternal Jew portrayed Jews as weak, sneaky, and filthy vermin. A similar technique (using fear-based radio broadcasts) was used in the Rwanda genocide by the Hutus to heighten the differences between themselves and the Tutsis.

Although the aforementioned cognitive perspectives are important contributors to the development of mass violence and genocide, they also suggest that an increased understanding of the "other" may in fact decrease feelings of enmity 
towards "them." Unfortunately, leaders can work to counter such understanding and instead fuel out-group-directed prejudice, discrimination, and violence. Much of Nazi propaganda was designed to increase the "otherness" of the Jew. Additionally, insignia were mandated to further increase that distinction and psychological separation as "other," while ghettoization and deportations sealed that distinction and physically limited any potential for future contact and understanding.

The manner by which we perceive the world around us can also aid in the formation of hatred and violence. Research suggests humans tend to use shortcuts or heuristics when processing information about the world (Nisbett and Ross, 1980). That is, people tend to avoid thinking very deeply about issues unless they directly impact their lives. Furthermore, people tend to seek out information that confirms their beliefs rather than material that disconfirms their views of reality-a phenomenon commonly referred to as the confirmation bias (Swann and Read, 1981). Such a bias was used by the nationalist media in Yugoslavia to present a distorted history that only served to fuel ethnopolitical hatreds. According to Helsinki Watch (1992, p 82), "The constant invocation of history to bolster ethnic nationalism has impeded the search for lasting and equitable political solutions to ethnic strife in Yugoslavia."

The tendency for humans to formulate connections, or illusory correlations, between unrelated phenomena further exacerbates the situation by providing seemingly credible evidence to support a belief system (Ward and Jenkins, 1965). Unfortunately, once our beliefs are formed, we are extremely reluctant to modify them. This phenomenon, referred to as belief perseverance, can account for the tenacity with which cultural groups hold onto their beliefs-however illogical they may seem to the outside observer (Ross et al., 1975).

Consequently, long-held beliefs about stigmatized groups can linger in a culture-particularly those cultures with a history of marginalization, bias, and/ or false belief systems regarding the "other." These factors can all be manipulated by the elite, particularly in totalitarian states, to further enhance the cultural divide and promote violence against a perceived threat. For example, "The Protocols of the Elders of Zion" continues to resurface and be used as evidence of a Jewish world dominance conspiracy, thus "confirming" what those with anti-Semitic inclinations believed they already knew. Subsequent attacks by the Rwandan Patriotic Front (RPF) following the beginning of the genocide was used by militant Hutus to reinforce the idea of the genocide's necessity (Des Forges, 1999).

Another shortcut that humans use when processing information is the fundamental attribution error (also called the correspondence bias). This error/bias is found across cultures and involves the tendency for individuals to attribute behavior to internal or dispositional causes, thus ignoring situational explanations (Ross, 1977). Consequently, when trying to explain genocide, individuals are more likely to focus blame solely on genocidal leaders or on the notion that age-old ethnic animosities are built into the genetic make-up of the two conflicting populations. For example, the Rwandan genocide or the collective mass murders in the former Yugoslavia are dismissed as ethnic hatreds dating back centuries and 
ingrained primordially into their "racial" identity. The fundamental attribution error frees humans from examining the social, political, and economic antecedents of genocide and mass violence as well as reduces a sense of bystander responsibility.

Finally, the tendency for individuals to make the fundamental attribution error, coupled with their desire to believe in a just world, leads people to blame the victim for whatever unfortunate event has befallen them (Lerner, 1980). For example, following WWII there were some who questioned whether Jews were partly responsible for the Holocaust. Additionally, over time perpetrators of mass violence further devalue their victims as a means to maintain their sense of a just world and to avoid cognitive dissonance (Staub, 2003). In summary, the typical manner by which people process information can potentially lead to the propagation of hate and can aid in the formation of genocide particularly if manipulated by the elite.

\section{Social influence}

The process by which we influence those around us and the situations under which we can be influenced are ripe targets for manipulation by genocidal leaders. At the most basic level, leaders may seek to shape the very culture. For example, many cultures value and encourage compliance, conformity, and obedience. Cultural rituals and standards, whether in religious, educational, corporate, or community structures, help to perpetuate compliance, conformity, and obedience. In addition, there are often very severe penalties for not adhering to these cultural milieus, ranging from ostracism and verbal aggression to physical violence (Levin, 1989). Thus, group members may feel pressure to engage in hatred and violence, knowing only too well the ramifications of not conforming. The pressure to comply, conform, or obey becomes even more salient upon the introduction of an authority figure. Milgram's $(1965,1974)$ obedience studies demonstrated the powerful effect an authority figure can have on our behavior. The presence of a strong authority figure, coupled with the foot-in-the-door technique (moving from minor acts of compliance to increasingly greater levels of involvement), is a proven technique that has been utilized by leaders to facilitate violence (Haritos-Fatouros, 1988).

Wartime propaganda, with its goal of convincing a nation to commit acts of aggression against an evil enemy, is a very well documented case where leaders have manipulated social psychological factors to further their own agenda. If such an appeal is successful, the act of war becomes consistent with societal values and even the most blatant propaganda is labeled "news" and deemed necessary to "support the troops." An examination of the ruling elite literature associated with each genocide clearly portrays images of the out-group as not only vile but also as an evil enemy. Nationalist media, for example, in Yugoslavia sought to evoke ethnic hatreds by falsifying historical and current events to raise fear and enmity while Serb school children were warned as to the dangers associated with Muslims by "teaching" about the fourteenth century battle of Kosovo, 
the Ustasha genocide during World War II, and betrayal by Muslims through conversion from their "true" Christian faith (Oberschall, 2001; Staub, 1999).

However, it is important to recognize the limitations of propaganda. In their review of the literature, Sears and Kosterman (1994) concluded that in most westernized societies, public exposure to political communications in the mass media is currently modest. In addition, the messages that are received typically only reinforce prior attitudes and are not particularly effective at changing attitudes (particularly those attitudes with a great deal of emotional ties). However, the authors go on to state that propaganda can be effective in several limited situations, most notably when recipients hold weak or ambiguous attitudes regarding the topic at hand or under massive exposure conditions (such as that seen during wartime). Consequently, the effect of propaganda is best measured over an extended period of time-when there is ample opportunity for the propaganda to effectively shape views about a particular topic. Thus, according to Oberschall (2001), ethnic polarizations increase the effectiveness of propaganda by wearing away structural protections. For example, Nazi propaganda became a mainstay of Germanic culture during the Nazi era due in part to the extensive use of antiSemitic images and ideas that evolved centuries earlier. Additionally, control of the mass media and the consistent messages of fear and hate mobilized greater ethnic division in both Rwanda and the former Yugoslavia. Yet ironically in Cambodia, the elimination of mass media facilitated the selective and constant reinforcement of ideas onto the population particularly children and young adults.

While wartime propaganda is an effective tool for increasing a nation's acceptance of violence, placing citizens into groups, whether military, quasi-military organizations, or even youth groups, can further serve to increase the propensity for violence. Groups tend to foster a sense of anonymity and eventually deindividuation among members (Festinger et al., 1952). Unfortunately, deindividuation often results in individuals becoming less self-aware, less responsible for their actions, and more likely to engage in violence if placed in a provocative situation (Prentice-Dunn and Rogers, 1989). Authoritarian governments often create new organizational structures and military groups designed to enhance deindividuation, compartmentalization of function, and consequently, diffusion of responsibility among its members. Uniforms and clearly identifiable proscribed rules for behavior facilitate state sponsored violence by enhancing deindividuation and conformity. For example, Hitler's youth and the Khmer Rouge both exemplify the potential for violence underlying these social influence processes.

In addition, very cohesive groups, like those that would exist in the upper echelons of a totalitarian power structure, tend to foster a style of decision-making that emphasizes maintaining group harmony. Consequently, groups that have this type of dynamic, labeled groupthink, tend to consistently agree with the leader, suppress realistic appraisals of the situation, and ignore possible alternative viewpoints (Janis, 1982). Thus, the potential exists within a very cohesive political group for a leader to advocate a policy of genocide without being met by significant resistance from group members. In fact, group polarization may occur, resulting in even more extreme viewpoints and actions. 
Several research studies have demonstrated that group discussion among likeminded individuals tends to enhance the initial leanings of the group (Moscovici and Zavalloni, 1969; Myers and Arenson, 1972). For example, liberal groups become even more liberal in their decisions following group deliberations. Unfortunately, the same can be said of prejudiced individuals, who adopt much more negative views regarding out-group members following group discussions (Myers and Bishop, 1970). Slobodan Milosevic was able to spread his nationalistic and genocidal agenda by having those with reform or moderate agendas expelled from the Central Committee. This purging furthered his rise to authoritarian power, improved his control of the state-operated media, and enhanced his image as a strong, nationalistic, and populist leader (Oberschall, 2001). By reducing dissident and even moderate voices, Milosevic was able to quickly move the country towards an agenda of ethnic cleansing_-including genocide.

\section{Social relations}

The social relations factors often discussed in relation to mass violence and genocide include prejudice, altruism, and aggression. Not surprisingly, the majority of research has focused on understanding the link between prejudice and violence. Consequently, several theories exist that purport to explain this connection.

One of the oldest attempts to understand the relationship between prejudice and aggression is scapegoat theory. This approach posits that when people are frustrated, such as during poor economic times, they tend to lash out at out-groupsparticularly those groups that have been marginalized in society (Allport, 1979). In one of the earliest examples of this theory, Hovland and Sears (1940) reported that the number of African Americans from the southern United States lynched in the late nineteenth and early twentieth century varied as a function of the price of cotton. When cotton prices were good, lynchings were down, whereas the opposite pattern held true when cotton prices were low. The researchers cited displaced aggression as the main culprit in this analysis.

According to scapegoat theory, groups that have a limited ability to defend themselves, such as women, children, and ethnic and religious minorities, tend to be the targets of aggression. For example, Jews in Nazi Germany were targeted based on their minority status and the existence of stereotypes consistent with the notion that they had a hand in Germany's economic downturn after WWI. Although the notion of scapegoating has tremendous appeal, the theory has fallen out of favor among researchers. The problem stems from the fact that contemporary researchers have found that frustrated individuals lash out against any outgroup-regardless whether the group is liked or disliked (Brown, 1995). In addition, scapegoat theory does not predict why a particular out-group is chosen as a target. For example, why weren't Latinos and Jews from the American South targeted to the same extent as African Americans during the time period in which Hovland and Sears conducted their research? Or why were the Twa not targeted for genocide in Rwanda? Obviously, other factors besides simply being an out-group influenced the decisions to target African Americans or Tutsis for 
extreme levels of persecution and genocide, respectively. As a result, many researchers have focused on the role realistic conflict theory plays in mass violence and genocide.

Realistic conflict theory is based on the premise that competition between groups for scarce resources leads to prejudice and may potentially result in conflict (LeVine and Campbell, 1972). It is important to note that realistic conflict theory is applied to situations where one group can achieve a goal at the expense of the other group (i.e. a zero-sum situation).

Realistic conflict theory has primarily been applied to situations in which groups compete for land, employment, and other factors that impact the economy (Esses et al., 1998). It is important to note that the authoritarian elite can make the aforementioned resources more salient to the populace in response to a perceived threat. Thus, Armenians who were largely assimilated members of the middle class were targeted during the economic crisis in the Ottoman Empire. Similarly, Jews were targeted by the Nazis due to their largely middle class and professional status during the economically troubled interwar period. Two major sources of export in Rwanda, coffee and tin, experienced sharp drops in price at the same time the country was experiencing rapid population growth resulting in extreme poverty as well as political infighting and competition between Hutu and Tutsi for resources.

To summarize, those in positions of power can manipulate a broad range of social psychological factors either or constructive or destructive actions. These can most easily be manipulated through a consolidation of governmental controls, the creation of new government organizations with specific political agendas, and control of the media. Additionally, leaders can use planned or unplanned incidents to further their ability to manipulate these social psychological factors. An airplane carrying the moderate Hutu leader is shot down, Cambodia is bombed by the United States, the Reichstag is laid ruin by flames-all events manipulated to promote political agendas.

\section{The path to mass violence and genocide}

While all the factors discussed above may be present in a situation, the question remains as to why some groups and nations function peacefully with their neighbors while others serve as a breeding ground for increasing levels of violence. Although individuals and populations are often reticent to commit extreme acts of violence without extensive provocation, history has demonstrated they can be led to engage in more innocuous acts of aggression with little difficulty. Consequently, leaders bent on leading their nation on the path to genocide must promote increasing levels of violence over time, while simultaneously maintaining the in-group's positive sense of self. To accomplish this task, leaders often systematically remove the rights once enjoyed by the target group, thus making it very difficult for the target group to resist the increasing levels of violence. In addition, a series of parallel processes are often enacted to ensure that in-group members are less willing to protest the treatment afforded to the target group. 
In fact over time, these parallel processes may actually increase the in-group's commitment to the path of mass violence.

\section{Basic stages on the path to mass violence and genocide}

The model which follows details seven basic stages that exist on the path to mass violence and genocide. Each of these stages is characterized by a specific level of violence with accompanying parallel process. However, it should be noted that the various stages in the path to mass violence and genocide are not absolute as levels and processes may overlap stages. Additionally, atrocities committed outside of a nation-state's boundaries may proceed at a faster rate and stages may be consolidated. Thus, it should be noted that this model does not represent an immutable pathway to mass violence and genocide but rather highlights increasing levels of risk for mass violence and genocide. The role that group cultural history, situational factors, social psychological factors, levels of violence, and parallel processes play in mass violence and genocide is portrayed in Figure 1.

\section{Stage one}

It is normative for in-groups to maintain stereotypes and negative attitudes toward an out-group. Over time, these stereotypes and negative attitudes can become institutionalized within a culture such that roles may become primarily associated with members of a particular group. Random acts of discrimination or crimes grounded in enmity towards an out-group member may occur but are not normative or condoned. In cultures characterized by an acceptance of psychological and physical violence, random acts of hate may be simply ignored or receive less attention than violent acts against members of the valued in-group. Leaders within such a culture may promote or discourage such acts and processes depending on their own agenda, the interest of the culture, and their own beliefs about the innate supremacy of the in-group. Thus, a cultural history that values violence as well as an ideology of supremacy provides the foundation for future movement along the path of violence.

\section{Stage two}

While the aforementioned set of conditions is far from an ideal state of mutual tolerance or peaceful coexistence, some cultures and groups proceed further down a path of greater violence. This movement is characterized by a loss of privilege and opportunity. Members of the out-group may be denied access to certain services, excluded from organizations, or limited in their ability to move past a glass ceiling in relation to educational opportunities or jobs. To facilitate this movement along the path to mass violence and genocide is the process of stigmatization. Beginning with an increase in stereotypes and derogatory images of the out-group, the process continues with the targeted group becoming further 


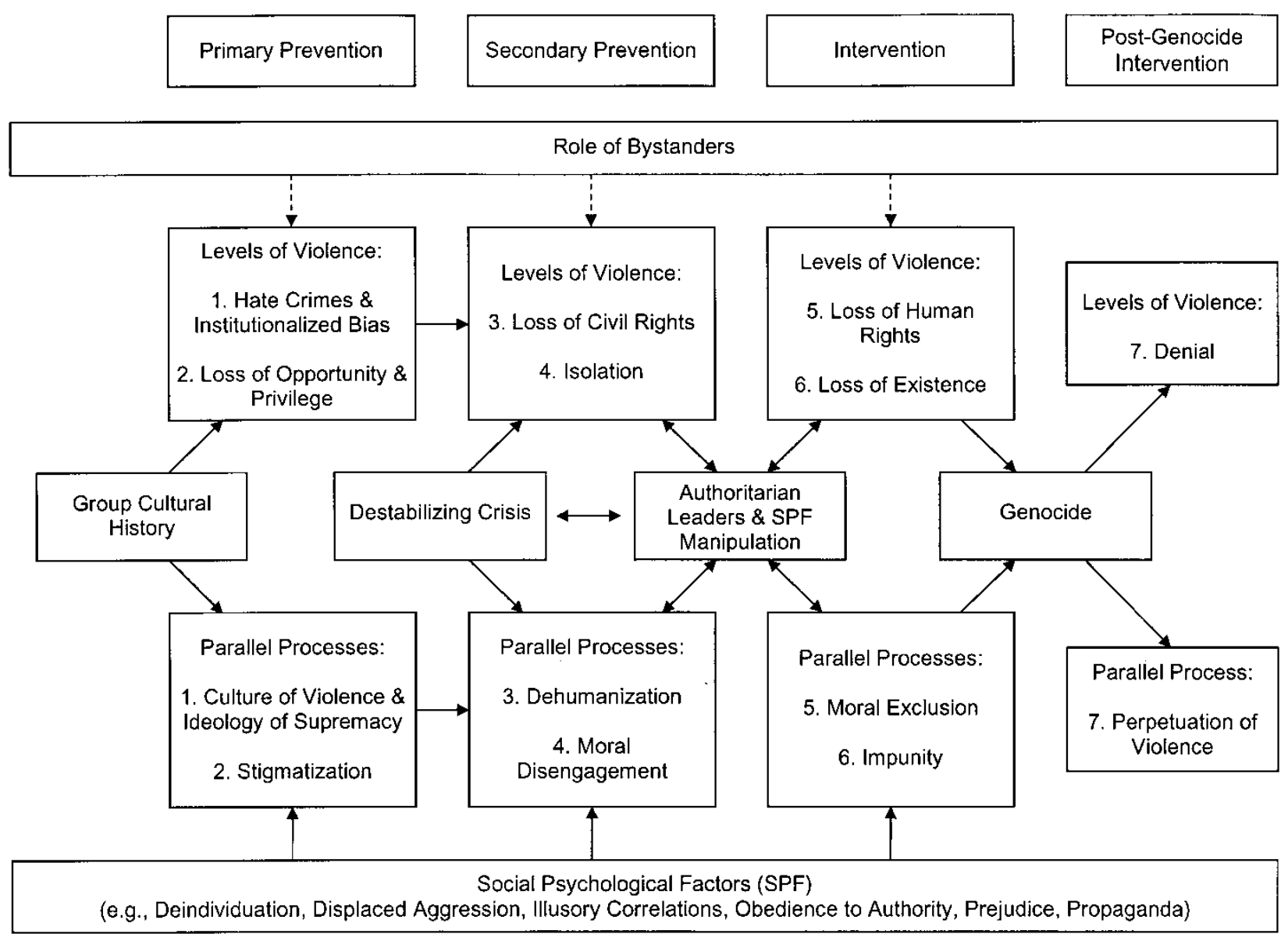

$\overline{\bar{u}} \quad$ Figure 1. Path to mass violence and genocide 
identified with negative attributes. This process of stigmatization may proceed through the use of identifying insignia or other means of classificatory processes. For example, during the Holocaust, Jews were forced to wear a yellow Star of David on their clothing or an armband, the letter J was stamped on their passports, and all had their first names changed to Israel or Sarah. Such measures increase the ease with which the targeted out-group can be moved along the path to mass violence and genocide. Unfortunately, these early actions are usually supported by easy and compelling rationales. Leaders and others of the elite may argue for the "necessity" of stigmatization and the resulting loss of privilege and opportunity. The rationales are bolstered as the stigmatization is grounded in existing stereotypes, prejudice, and bias. For example, the portrayal of Jews during the Holocaust as parasites upon the nation predates Nazi-occupied Europe by several centuries.

\section{Stage three}

If stigmatization with accompanying loss of opportunity and privilege is accepted by an in-group or population, it is easier to move on to step three which is characterized by loss of basic civil rights. In this case, members of the out-group may be denied citizenship or the right to vote, may not be allowed to own land or operate a business, or may find that certain laws apply differently to themselves relative to the in-group. To facilitate movement towards loss of civil rights in relation to a target group, leaders and other elite will promote increasing levels of dehumanization. This process of dehumanization begins with increased promotion of stereotypes and negative images of the out-group. Dehumanization is often a necessary tool to reduce the cognitive dissonance that may occur when individuals behave negatively toward other human beings (Berscheid et al., 1968). Propaganda is a vital tool used by the in-group elite to stigmatize and dehumanize the outgroup. In addition, propaganda may present the out-group as an imminent threat to the well-being or existence of the in-group. For example, the out-group may be presented as a parasite stealing the life-blood of the in-group, in partnership with the demonic forces, as various forms of vermin, or a destructive, invading force. Armenians during the Ottoman Empire as well as Tutsis in Rwanda were portrayed as being in league with hostile, invading enemies thus representing "alien" intruders needing of elimination. The Eternal Jew portrayed Jews as a parasitic society with odd religious practices, who spread like rats across the globe disseminating plague in their path. This film combined the dehumanization theme with a call for the removal of this "cancer from the body of Germany." Unwittingly, when individuals write of genocide as the extermination of an entire people, they retain the vermin metaphor used by the perpetrator.

\section{Stage four}

If little protest is raised in regard to the loss of civil rights, it becomes easier to force isolation upon an out-group. Ghettoization, deportations, and ethnic cleansing of a region are examples of out-group isolation strategies. The rationale for 
isolating the out-group is supported through propaganda. Such misinformation is necessary in order to protect the self-esteem of the in-group. Additionally, a selffulfilling prophesy is created to further the rationale for isolating the out-group. Due to the previous loss of opportunity and civil rights some members of the targeted out-group may begin to reflect the effects of such losses (e.g. effects of poverty) and thus serve to reinforce the stereotypic images as portrayed by the in-group through propaganda. Of course, the path to genocide could not be taken without the underlying process of moral disengagement. As the out-group is perceived as increasingly different or sub-human through the process of dehumanization, there is a concomitant willingness among the populace to disengage morally (Bandura, 1998). Euphemistic language can facilitate the process of disengagement as it is easier to turn a blind eye to the deportation of one's neighbor "to the east" as opposed to deportation "to their death." In addition, the process of moral disengagement is facilitated by the natural tendency for individuals to blame the victim via a belief in a just world. According to researchers, individuals who are victimized are more likely to be devalued and are likely to be blamed for their misfortune. Moreover, if such misfortune is perceived to result in extended suffering, the degree of blame increases (Correia et al., 2001; Lerner and Simmons, 1966). Thus, phrases such as "the Jews brought the Holocaust upon themselves" and "the Turks were merely responding to the civil war threat posed by the Armenians" exemplify such blaming of the victim in an attempt to maintain a belief in a just world. This tendency to blame the victim may be facilitated by propaganda and justified by the elite.

\section{Stage five}

The loss of civil rights and isolation that characterize previous stages quicken the movement along the path to genocide towards the deprivation of basic human rights to the out-group. Individuals in the out-group may be denied education, access to adequate food and shelter, and relegated to subsistence living. The more isolated the targeted out-group has become, the easier it is for the majority population to feign ignorance of these events.

Facilitating the willingness of the population to ignore the impending genocide is the process of moral exclusion (Opotow, 1990). In other words, the moral principles that may be applied to one's own group no longer pertain to those outside of the group. For example, it is unfortunate but acceptable to kill an enemy during war when the soldier is identified as a member of the threatening out-group. However, it is even easier to kill someone who has been defined as existing outside of the human and thus moral realm. Words such as "dink," "slant," or "gook" resonate more as curses than identifiers of human beings (Erikson, 1996). On the path to mass violence and genocide, the process of disengagement morally becomes complete as the victim becomes excluded entirely from the normal moral realm. The victims are no longer viewed as human but rather vermin to be exterminated or infected tissue needing to be excised. 
Stage six

Finally, members of the out-group may find their very existence threatened. Whether a group or nation moves down the path to genocide is decided in part by whether the aggression will be met with acceptance or punishment. An atmosphere of impunity increases the probability of violence (Roth et al., 1999). In the late 1800s and early 1900s, the Ottoman Empire began a campaign of ethnic cleansing against the Armenian population. World outrage and the threat of sanctions, particularly by Great Britain, quelled the destruction that had already led to the loss of an estimated 200,000 Armenian lives (Smith, 1999; Staub, 1989). However, with the advent of WWI, the risk of sanctions became irrelevant and the Armenian genocide occurred unabated. So too, millions of Jews, Roma and Sinti, Cambodians, Bosnians, Tutsis, and others were murdered as the passive world community created an atmosphere of impunity.

\section{Stage seven}

The final insult in the path to genocide is the denial that the genocide even occurred. Denial of genocide also continues the original harm as it is a further assault on the victims of the genocide-it is an assault on the memory of those victims. At the very least, we should acknowledge that these individuals existed and the horrors surrounding their deaths. To argue that they never lived and/or that they were never murdered when the historic record is so clear is harmful and particularly painful for survivors and their communities. In the extreme, it is a continuation of hatred and has as its base destructive motivations (e.g. the denial exhibited by white supremacist and neo-Nazi groups). On its most banal level, it is a further assault and it does nothing to resolve unhealed group trauma but rather adds to the suffering, and inhibits any sort of future reconciliation. Additionally, the individual perpetrators of such violence are themselves harmed simply by the action of having engaged in injuring or ending the lives of other human beings. Failure to look into the abyss of one's own actions inhibits any form of healing on the part of perpetrator and perpetrator groups.

Bear in mind that with each step along the path to genocide, intervention becomes more difficult. Early on, leaders of groups or nations may be more amenable to intervention as they are held accountable for their actions. Additionally, the population may be more open to other forms of societal change, assistance for help with crisis, or new leaders. However, later in the process, intervention becomes more difficult. Leaders and the elite who have been moving the society along the path to mass violence and genocide with a sense of impunity will have little motivation to change as they may now see themselves as being potentially held accountable for genocide and other crimes against humanity. Additionally, over time the population will be more strongly committed to the path to mass violence and genocide due to factors such as cognitive dissonance. Finally, time enables authoritarian leaders to solidify their control of various aspects of a society from the media to the economy making intervention more difficult. 
Each of the stages described above can be examined in the context of the path taken by the Nazis following Hitler's promotion to Chancellor. Hitler did not begin his campaign against the Jews in Germany with genocide, but rather began with the organization of a small, one-day strike against Jewish businesses, and progressed to the passage of a law removing Jews from certain civil service positions. He closely watched the outcome of these actions, and since most Germans did not respond publicly in a negative fashion, he had his foot in the door. Later, the Nuremberg Laws were passed, which resulted in the loss of a large number of basic civil rights for Jews, including citizenship and the right to live where they chose. Jews were placed in ghettos, conscripted into forced labor, and deported to various sites within the Nazi camp system. The removal and isolation of Jews from non-Jews within mainstream society facilitated movement down the path to mass violence and the loss of fundamental human rights for Jews was not far behind. Basic human rights such as adequate food, water, health care, sanitation, protection from the elements, as well as freedom from slavery and forced harsh labor were systematically denied within the ghettos and concentration camps resulting in the death of many Jews. The Nazis through the creation of death squads and finally death camps insured the final step down the path to genocide. Hitler, of course, did not invent this path to genocide; rather, it is one seen often in history, from the destruction of America's indigenous populations to the genocide of the Armenians within the Ottoman Empire. In fact, the denial of atrocities such as the genocide of the Armenians facilitated the process of genocide during the Holocaust (Smith, 1992).

\section{Role of bystanders}

The final primary factor that influences the path to mass violence and genocide is the role of bystanders. Bystanders have the ability to quell violence through action or by virtue of their presence. Unfortunately, they also have the ability to provide tacit approval for hatred, discrimination, and violence, through inaction. In relation to genocide, bystanders include not only individuals within a nationstate but also individuals, groups, and nations outside of the immediate sphere of destructive action. Of course, it is difficult to make claims where intervention resulted in the prevention of mass violence. The absence of violent action alone fails to demonstrate effectiveness of intervention as no definitive inevitability of genocidal actions can be proven. For example, it is impossible to determine if actions taken by NATO forces in Kosovo and subsequent installment of international peacekeepers prevented further mass violence and an escalation into large-scale genocide in this region of the former Yugoslavia. However, there is substantial evidence that genocides which were ignored were able to proceed with impunity where action most likely could have prevented large-scale slaughter. While the world watched as thousands of Tutsis were being slaughtered each day in Rwanda, the Clinton Administration and the United Nations both fervently worked to distance themselves from the atrocities and stridently avoided the use of the term genocide which would have necessitated action. Germany during World 
War I, allied with the Young Turks, tacitly approved of the actions against the Armenian and thus the annihilation proceeded unabated. Many have questioned whether the Holocaust would have occurred if the world community had responded to earlier aggressive behavior with direct involvement as opposed to appeasement. This question is difficult to answer, but most certainly fewer Jews would have died if some action had been taken. Simply opening the doors of immigration would have saved untold numbers of lives.

The question of why individuals fail to intervene in times of need, becoming instead passive bystanders, has been addressed in a variety of research studies (Piliavin et al., 1981). Rationales for inaction include diffusion of responsibility and pluralistic ignorance. In times of crisis, individuals in crowds are less likely to intervene, as personal responsibility to help becomes diluted. Additionally, we tend to look to others for assistance in understanding a situation and may decide that if others appear unconcerned, then there is little reason for intervention. Once committed to non-action, it becomes increasingly difficult for intervention to occur due to cognitive dissonance and a belief in a just world. These and other reasons may deter bystanders from acting or providing aid once committed to a pattern of inaction.

On an international level, additional dynamics influence the action of bystander nations. Lack of will, economic and political self-interest, national sovereignty, and prejudice have all stood in the way of action in the face of violence. For example, it has largely been argued the United States failed to intervene during the genocide of the East Timorese in the mid-1970s for fear that the Indonesian government would fall into communist hands if opposed (Dunn, 1997). Similarly, many nations failed to take action as the Iraqi government gassed at least 100,000 Kurds given the more pressing adversary at the time was perceived to be Iran with whom Iraq was in conflict (Horowitz, 1999; Staub, 2003). Even post-genocide, disparities have appeared in relation to the amount of aid provided to refugees. This issue became apparent when substantially more aid was provided to refugees from the Balkans than African refugees (Miller and Simmons, 1999).

The most parsimonious explanation for this disparity is the obvious difference in race among the refugees. Interestingly, the rationale often provided by nonresponsive nations as to their unwillingness to intervene in former Yugoslavia or Rwanda is the fallacy that no action is possible, since these groups have been "fighting since the beginning of time." This is an interesting twist on the notion of diffusion of responsibility, because not only is responsibility diffused across nations, but it is also diffused across time.

Nonetheless after the Holocaust, the phrase "Never Again" resounded on the lips of Jews and Christians alike. Sadly, the words "Never Again" ring hollow in the face of subsequent mass violence and genocide, in large part due to inaction by bystanders at all levels from the individual to that of the nation-state. Clearly, words alone will not bring about a more peaceful global community that eschews mass violence and genocide. Rather a multifaceted approach to prevention must be explored and implemented. 


\section{Prevention and intervention}

While it may appear that mass violence, whether committed in the name of colonialism, fascism, imperialism, religion, self-interest or other rationales, is an inevitable result of the human "survival of the fittest," this is an inaccurate perception. Indeed there are many steps that can be taken to reduce mass hatred, violence, and genocide. Such atrocities are by no means an inevitability of human interaction. However, for prevention to really be successful an integrated approach must be taken and levels of prevention as well as intervention must be discussed. Unfortunately, when most individuals discuss prevention, they are really focusing on intervention given the flames of genocide are already burgeoning if not engulfing a region or people. As portrayed in Figure 1, prevention in relation to the psychosocial model presented in this article can be broken down into three distinct phases: primary prevention, secondary prevention, and intervention (sometimes referred to as tertiary prevention).

\section{Primary prevention}

If we truly want to work toward building cultures of peace it is imperative that coordinated efforts in four broad areas be undertaken. First, historic animosities and patterns of disparity must be addressed. Without efforts to address historic injustices, tensions and long-held prejudices will continue to fuel inter-group animosities. One of the primary reasons for this ongoing division is the magnitude gap as discussed by Baumeister (1997). A difference in perception of harm exists between victims and perpetrators. Victims perceive the extent of the harm as greater than the perpetrator and view all actions on the part of the perpetrator, including those resulting in accidental outcomes, as being intentional. In addition, victims also feel the reverberations of the harm extending over a much longer period of time and occasionally intergenerationally. Ironically, perpetrators tend to perceive themselves as victims in a reversal of morality. Because of these differences in perception, victims' retaliatory responses tend to be viewed as out of proportion by the original perpetrators, thus enhancing the perpetrators perception that they are in fact being victimized. This may result in further aggression directed towards the original victims which ultimately escalates the cycle of violence. For groups to move beyond this pattern or at best a violence stalemate, each group must come together to understand the partisan perceptions of the "other." Additionally, each group, particularly the dominant group, must acknowledge the harm caused and make efforts towards restorative justice.

Concomitantly with the process of addressing historic patterns and animosities, the second component of building a culture of peace involves the promotion of positive relationships between groups. There is an extensive body of literature that suggests simple contact between groups does little to reduce negative intergroup relations (Amir, 1976). While there is little support for the notion that contact, in and of itself, will decrease the likelihood of inter-group conflict, there is a growing body of literature that suggests that contact, if coupled with 
tactics such as increasing personalization, celebrating the differences between groups, and introducing stereotype-disconfirming evidence, can enhance intergroup relations (Hewstone, 1996). In addition, relationships that are developed out of the necessity for inter-group cooperation to achieve a goal have been found to reduce prejudice and promote positive relationships (Gaertner et al., 1990). The key is the development of deep and meaningful relationships and not just superficial or incidental contact (Staub, 2003).

It is important to note that the process of inter-group exchange is facilitated by knowledge and preparation prior to inter-group contact (Staub, 1989). Education is the third primary element involved in creating a culture of peace. Educational efforts need to focus on peace education including the teaching of non-violent conflict resolution skills. Conflict is a necessary and vital component of life; violent conflict resolution is not. Therefore, individuals, particularly children and adolescents, need to be taught the difference between various conflict resolution styles and the promotion of congruent problem-solving skills. Additionally, children need to be taught both independent and critical thinking skills. This is needed to counter the tendency in humans towards blind obedience to authority and conformity in situations supporting the promotion of intra- and inter-personal violence.

As a component of peace education, children and indeed communities need to become more familiar with and develop a value for fundamental human rights and the extension of these rights to all peoples. According to the Honorable Mary Robinson (2003), former UN Commissioner for Human Rights, there is a strong correlation between economic development and human rights in every region of the world. While the direction of causality is unclear, Robinson argues that the promotion of universal human rights within a culture advances economic development. If Robinson's observations are correct, human rights education would serve a twofold purpose. First, the adoption of universal human rights would promote peaceful coexistence and respect across cultures and peoples. Second, it would assist in combating the difficulties associated with economic crisis as a precursor to mass violence and genocide.

Education related to the teaching of tolerance and particularly an appreciation of diversity must be provided in schools, religious institutions, and other community organizations. Children who develop prejudicial attitudes and biases are more likely to become adults with these same belief systems. Thus, schools and universities are natural environments for education about hate, tolerance, and diversity. Programs such as $A$ World of Difference are a good place to begin for schools unfamiliar with diversity education (Anti-Defamation League, 2002). It is important to note that teens and young adults are particularly susceptible for recruitment into organizations of hate and violence. Thus, diversity educations need to include "inoculation" against potential recruitment. Researchers have successfully inoculated children to resist attacks on cultural truisms such as brushing one's teeth (McGuire, 1964), refusing to give in to peer pressure to smoke (McAlister et al., 1980), and engaging in drug use (Ellickson and Bell, 1990). Finally, for children to value others, they must value themselves. However, while it is important that positive self-esteem be developed in children and youth, one must ensure that 
the self-esteem is grounded in actual accomplishments and demonstrated abilities. Baumeister (1997) argues that inflated self-esteem when threatened is a source of potential violence as often evidenced in gangs and other destructive groups. Our schools and community must focus on teaching prosocial behavior and movement along a path of caring, contribution, and social action/justice. Just as individuals can begin and move down a path of hate, violence, and destruction, research has demonstrated that individuals can just as easily move down a path of benevolence (Staub, 1989). Finally, cultures must move toward the development of democratic forms of government and accepting pluralistic cultures. Ample evidence exists demonstrating the dangers associated with authoritarian forms of government and cultures characterized by homogeneity of peoples and beliefs (Rummel, 1996; Staub, 1989).

\section{Secondary prevention}

Secondary prevention is necessary when situational factors predictive of genocide or other forms of mass violence are present. As noted previously, crisis can be very destabilizing both for individuals and cultures. Thus, the international community needs to be more responsive to the needs of societies during times of crisis whether economic, political, or environmental. Such aid may not only assist in the stabilization of a community but also decrease the likelihood that an authoritarian form of government will emerge as a reaction to such strife. Additionally, when nations have already begun to move down the path to mass violence and genocide, the international community must not remain a passive bystander. Political pressure needs to be brought to bear upon those governments with potentially destructive agendas. Such destructive agendas may be apparent through the loss of civil rights of a target group within a nation-state (e.g. new restrictive laws or deportations) or the development of an infrastructure with a high probability of destructive goals (e.g. creation of the concentration camps or Hutu militant's purchase of vast quantities of machetes). Alternative strategies for internal national development need to be provided so as to entice governments to move from authoritarian to more democratic forms of governmental structures. Boycotts and sanction have the potential to affect change in oppressive governments if used judiciously bearing in mind the nature of partisan perceptions. However, such efforts are more effective early on in the development of a pre-genocidal state. Unfortunately, such efforts will be less effective if authoritarian leaders perceive themselves to have reached a point of no return where change increases the potential for their own national or international prosecution and punishment.

Given the powerful influence the media has in the long-term development of a pre-genocidal state, alternate forms of media and media transmission must be disseminated within the at-risk country. In the absence of counter information, individuals are more likely to believe the existing propaganda. Consequently, individuals within pre-genocidal states need to be exposed to alternative voices to allow individuals to more critically evaluate their perspectives. Additionally, 
the strategies outlined under primary prevention need to be implemented to further reduce the risk for mass violence and genocide.

\section{Intervention}

When individuals and groups within a culture begin to be deprived of basic civil and human rights, direct intervention becomes necessary. Unfortunately, the twentieth century represented a chronicle of non-involvement. Therefore, clear-cut strategies and mechanisms for intervention have not yet been developed. The Universal Declaration of Human Rights and the Convention on Genocide provide a framework for the identification of pre-genocidal and genocidal cultures. What is needed now is a formula for action when such cultures have been identified. While the presence of international special envoys and advisory teams has been useful in quelling the growth of violence, there have been times when military action should have been implemented (Carnegie Commission on the Prevention of Deadly Violence, 1997). Consequently, Fein (1994b), Mendlovitz and Fousek (1996), and others have called for the creation of a permanent UN or other international force to intervene and enforce the Genocide Convention. It should be noted that in addition to the development of specific strategies and mechanisms for intervention, the UN and the global community must be invested in action. The long-term benefit of such an investment is the reduction of future violence due to a decreased number of victimized individuals whose trauma may promote future violence, a reduction in number of perpetrators whose actions may lead to a further commitment to violence, and the elimination of the atmosphere of impunity that promotes violence. The United Nations and international governments are not alone in identifying at-risk, pre-genocidal, or genocidal nation-states. Critical support can be provided by NGOs such as Amnesty International and Human Rights Watch.

The UN and others can use these organizations to make informed decisions relative to intervention. Additionally, there are organizations specifically focused on the identification of pre-genocidal and genocidal states that alert policy makers and others to atrocities being committed around the globe. Genocide Watch, the International Campaign to End Genocide, and the Committee on Conscience all work to alert policy makers and focus on the agenda of eliminating genocide. Of course, these policy makers must be committed to a pattern of action to reduce violence and increase efforts aimed at restorative justice.

When gross human rights violations, crimes against humanity, or genocide have been identified, extreme political pressure must be placed upon the responsible governments or quasi-governmental states. Boycott and sanction may be attempted first. However, if such actions are ineffective, then armed intervention may be the only recourse to save lives and prevent further destruction. However, it should be stressed that such actions may only be necessary if attempts at primary and secondary prevention have not been undertaken. 


\section{Post-genocide intervention}

The wounds of genocide run deep in survivors and must be addressed to prevent future violence. So too the scars of violence change the perpetrators as well as bystanders complicit through inaction. While beyond the scope of this paper, issues that need to be addressed include restoring a sense of justice, healing the wounds of the victims, and addressing the effects of perpetrator complicity on the culture. International tribunals such as the International Criminal Tribunal for the Former Yugoslavia (ITCY) and the International Criminal Tribunal for Rwanda (ICTR) function to bring perpetrators to justice. Unfortunately, this system of tribunals has not been uniformly applied (Minow, 1998). For example, efforts to form a tribunal in Cambodia to try the perpetrators of the Cambodian genocide have been largely unsuccessful and other genocides have been largely ignored or denied. Additionally, these tribunals have faced the issues of victor's justice, retroactivity of legal statutes, selectivity in relation to prosecution, and political factors influencing the establishment and functioning of the courts. Truth Commissions increase the likelihood of a full disclosure of facts and events, provide a forum for victims to voice their story and pain, and open the path to reconciliation and cultural reconstruction. Unfortunately, as only the primary perpetrators may be held accountable for their actions in a formal manner, many victims feel that full justice has been denied.

Models such as those being developed by Staub (2003) and others (e.g. Trauma Research Education and Training Institute, 2004) are aimed at post-genocide reconciliation and reconstruction. Such efforts must be undertaken and research conducted concerning their effectiveness. It is clear that without such work, the wounds of genocide continue to fester in all parties creating only the future potential for genocidal violence. Clearly, the mass violence and genocide in both Burundi and Rwanda stem from unresolved disparities resulting from colonization and a spiraling cycle of subsequent violence.

It should be noted that the current model is not a mathematical formulation for the prediction of genocide. Rather it highlights risk factors associated with the potential for genocidal action as well as other forms of mass violence and provides information relative to strategies aimed at prevention and intervention. It is imperative that such efforts be undertaken, that individuals, communities, nations, and international organizations not stand idly by in the face of destruction. Rather, we all need to become involved in the development of a global community characterized by international cooperation and support during times of crisis, non-violent conflict resolution, the protection of fundamental human rights, and peace.

\section{Bibliography}

Adalian, R. P. (1997) "The Armenian genocide," in S. Totten, W. S. Parsons and I. Charny, eds, Century of Genocide: Eyewitness Accounts and Critical Views (New York: Garland), pp 41-77.

Allport, G. W. (1979) The Nature of Prejudice, 25th anniversary edn (Reading, MA: Addison Wesley).

Amir, Y. (1976) "The role of intergroup contact in change of prejudice and ethnic relations," in P. A. Katz, ed., Towards the Elimination of Racism (Elmsford, NY: Pergamon Press), pp 245-308. 
Anti-Defamation League (2002) World of Difference Program, available online at: 〈http://www.adl.org/education/edu_awod/default_awod.asp $\rangle$ (accessed May 25, 2004).

Bandura, A. (1998) "Mechanism of moral disengagement," in W. Reich, ed., Origins of Terrorism: Psychologies, Ideologies, Theologies, States of Mind (Baltimore, MD: Johns Hopkins University Press), pp 161-191.

Bass, B. M. and Stogdill, R. M. (1990) Bass and Stogdill's Handbook of Leadership: Theory, Research and Managerial Applications, 3rd edn (New York: Free Press).

Baumeister, R. F. (1997) Evil: Inside Human Violence and Cruelty (New York: W. H. Freeman).

Baumeister, R. F., Smart, L. and Boden, J. M. (1996) "Relation of threatened egoism to violence and aggression: the dark side of high self-esteem," Psychological Review, Vol 103, No 1, pp 5-33.

Berscheid, E., Boye, D. and Walster (Hatfield), E. (1968) "Retaliation as a means of restoring equity," Journal of Personality and Social Psychology, Vol 10, No 4, pp 370-376.

Blumer, H. (1958) "Race prejudice as a sense of group position," Pacific Sociological Review, Vol 1, No 1, pp 3-7.

Bobo, L. and Hutchings, V. L. (1996) "Perceptions of racial group competition: extending Blumer's theory of group position to a multiracial social context," American Sociological Review, Vol. 61, No 6, pp 951-972.

Brewer, M. B. (1979) "In-group bias in the minimal intergroup situation: a cognitive-motivational analysis," Psychological Bulletin, Vol 86, No 2, pp 307-324.

Brown, R. (1995) Prejudice: Its Social Psychology (New York: Free Press).

Carnegie Commission on the Prevention of Deadly Conflict (1997) Preventing Deadly Conflict: Final Report (New York: Carnegie Corporation).

Chemers, M. M. and Ayman, R., eds (1993) Leadership Theory and Research: Perspectives and Directions (San Diego, CA: Academic Press).

Correia, I., Vala, J. and Aguiar, P. (2001) "The effects of belief in a just world and victim's innocence on secondary victimization, judgements of justice and deservingness," Social Justice Research, Vol 14, No 3, pp 327-342.

Des Forges, A. (1999) Leave None to Tell the Story: Genocide in Rwanda (New York: Human Rights Watch).

Dodge, K. A., Price, J. M., Bachorowski, J. and Newman, J. P. (1990) "Hostile attributional biases in severely aggressive adolescents," Journal of Abnormal Psychology, Vol 99, No 4, pp 385-392.

Dunn, J. (1997) "Genocide in East Timor," in S. Totten, W. S. Parsons and I. Charny, eds, Century of Genocide: Eyewitness Accounts and Critical Views (New York: Garland), pp 264-290.

Ellickson, P. L. and Bell, R. M. (1990) "Drug prevention in junior high: a multi-site longitudinal test," Science, Vol 247, No 4948, pp 1299-1305.

Erikson, K. (1996) “On pseudospeciation and social speciation,” in C. B. Strozier and M. Flynn, eds, Genocide, War and Human Survival (Lanham, MD: Rowman \& Littlefield), pp 51-58.

Esses, V. M., Jackson, L. M. and Armstrong, T. L. (1998) "Intergroup competition and attitudes toward immigrants and immigration: an instrumental model of group conflict," Journal of Social Issues, Vol 54, No 4, pp 699-724.

Fein, H. (1994a) "Genocide, terror, life integrity and war crimes: the case for discrimination," in G. J. Andreopoulos, ed., Genocide: Conceptual and Historical Dimensions (Philadelphia: University of Pennsylvania Press), p 97.

Fein, H. (1994b) The Prevention of Genocide (New York: City University of New York).

Festinger, L., Pepitone, A. and Newcomb, T. (1952) "Some consequences of deindividuation in a group," Journal of Abnormal and Social Psychology, Vol 47, pp 382-389.

Gaertner, S. L., Mann, J. A., Dovidio, J. F., Murrell, A. J. and Pomare, M. (1990) "How does cooperation reduce intergroup bias?" Journal of Personality and Social Psychology, Vol 59, No 4, pp 692-704.

Haritos-Fatouros, M. (1988) "The official torturer: a learning model for obedience to the authority of violence," Journal of Applied Social Psychology, Vol 18, No 13, pp 1107-1120.

Hate Groups USA (1998) Video recording. Directed by Z. Chughtai (Princeton, NJ: Films for the Humanities \& Sciences).

Helsinki Watch (1992) War Crimes in Bosnia-Herzegovina (New York: Human Rights Watch).

Hewstone, M. (1996) "Contact and categorization: social psychological interventions to change intergroup relations," in C. Macrae, C. Stangor and M. Hewstone, eds, Stereotypes and Stereotyping (New York: Guilford Press), pp 323-368.

Hirsch, H. (1995) Genocide and the Politics of Memory: Studying Death to Preserve Life (Chapel Hill, NC: University of North Carolina Press).

Hollander, E. P. (1985) "Leadership and power," in G. Lindzey and E. Aronson, eds, Handbook of Social Psychology, Vol 2, 3rd edn (New York: Random House), pp 485-537.

Horowitz, I. L. (1999) "Science, modernity and authorized terror: reconsidering the genocidal state," in L. Chorbajian and G. Shirinian, eds, Studies in Comparative Genocide (New York: St. Martin's Press), p 24. 
Hovland, C. I. and Sears, R. R. (1940) "Minor studies of aggression: VI. Correlation of lynchings with economic indices," Journal of Psychology, Vol 9, pp 301-310.

Janis, I. L. (1982) Groupthink, 2nd edn (Boston: Houghton Mifflin).

Kiernan, B. (1997) "The Cambodian genocide: 1975-1979," in S. Totten, W. S. Parsons and I. Charny, eds, Century of Genocide: Eyewitness Accounts and Critical Views (New York: Garland), pp 334-371.

Kressel, N. (1996) Mass Hate: The Global Rise of Genocide and Terror (New York: Plenum Press).

Landis, D. and Boucher, J. (1987) "Themes and models of conflict," in J. Boucher, D. Landis and K. A. Clark, eds, Ethnic Conflict: International Perspectives (Newbury Park, CA: Sage), pp 18-32.

Leonard, K. E. and Taylor, S. P. (1981) "Effects of racial prejudice and race of target on aggression," Aggressive Behavior, Vol 7, No 3, pp 205-214.

Lerner, M. J. (1980) The Belief in a Just World: A Fundamental Delusion (New York: Plenum).

Lerner, M. and Simmons, C. (1966) "Observer's reaction to the 'innocent victim': compassion or rejection?" Journal of Personality and Social Psychology, Vol 4, No 2, pp 203-210.

Levin, J. M. (1989) "Reaction to opinion deviance in small groups," in P. B. Paulus, ed., Psychology of Group Influence, 2nd edn (Hillsdale, NJ: Erlbaum), pp 187-231.

LeVine, R. A. and Campbell, D. T. (1972) Ethnocentrism: Theories of Conflict, Ethnic Attitudes and Group Behavior (New York: Wiley).

Lifton, R. (1989) Thought Reform and the Psychology of Totalism (Durham, NC: University of North Carolina Press).

Mamdani, M. (2001) When Victims Become Killers: Colonialism, Nativism and the Genocide in Rwanda (Princeton, NJ: Princeton University Press).

McAlister, A., Perry, C., Killen, J., Slinkard, L. A. and Maccoby, N. (1980) "Pilot study of smoking, alcohol and drug abuse prevention," American Journal of Public Health, Vol 70, No 7, pp 719-721.

McGuire, W. J. (1964) "Inducing resistance to persuasion," in L. Berkowitz, ed., Advances in Experimental Social Psychology, Vol 1 (New York: Academic Press), pp 192-229.

Meindl, J. R. and Lerner, M. J. (1984) “Exacerbation of extreme responses to an out-group," Journal of Personality and Social Psychology, Vol 47, No 1, pp 71-84.

Mendlovitz, S. and Fousek, J. (1996) "The prevention and punishment of the crime of genocide," in C. B. Strozier and M. Flynn, eds, Genocide, War and Human Survival (Lanham, NJ: Wowman \& Littlefield), pp 137-152.

Milgram, S. (1965) "Some conditions of obedience and disobedience to authority," Human Relations, Vol 18, No 1, pp 57-76.

Milgram, S. (1974) Obedience to Authority (New York: Harper and Row).

Miller, N. E. and Bugelski, R. (1948) "Minor studies of aggression: II. The influence of frustrations imposed by the in-group on attitudes expressed toward out-groups," Journal of Psychology, Vol 25, pp 437-442.

Miller, T. C. and Simmons, A. M. (1999) "African camps are much worse off," Chicago Sun-Times, May 23, p 6.

Minow, M. (1998) Between Vengeance and Forgiveness: Facing History after Genocide and Mass Violence (Boston: Beacon Press).

Moscovici, S. and Zavalloni, M. (1969) “The group as a polarizer of attitudes,” Journal of Personality and Social Psychology, Vol 12, No 2, pp 125-135.

Myers, D. G. and Arenson, S. J. (1972) "Enhancement of dominant risk tendencies in group discussion," Psychological Reports, Vol 30, No 2, pp 615-623.

Myers, D. G. and Bishop, G. D. (1970) "Discussion effects on racial attitudes," Science, Vol 169, No 3947, pp 778-789.

Nisbett, R. E. and Ross, L. (1980) Human Inference: Strategies and Shortcomings of Human Judgment (Englewood Cliffs, NJ: Prentice Hall).

Oberschall, A. (2001) "From ethnic cooperation to violence and war in Yugoslavia," in D. Chirot and M. E. P. Seligman, eds, Ethnopolitical Warfare: Causes, Consequences and Possible Solutions (Washington, DC: American Psychological Association).

Opotow, S., ed. (1990) "Moral exclusion and injustice: an introduction," Journal of Social Issues, Vol 46, No 1, pp $1-20$.

Piliavin, J. A., Dovidio, J. F., Gaertner, S. L. and Clark III, R. D. (1981) Emergency Intervention (New York: Academic Press).

Pratto, F., Sidanius, J., Stallworth, L. M. and Malle, B. F. (1994) "Social dominance orientation: a personality variable predicting social and political attitudes," Journal of Personality and Social Psychology, Vol 67, No 4, pp 741-763.

Prentice-Dunn, S. and Rogers, R. W. (1989) "Deindividuation and the self-regulation of behavior," in P. B. Paulus, ed., Psychology of Group Influence, 2nd edn (Hillsdale, NJ: Erlbaum), pp 87-109.

Robinson, M. (2003) Public lecture, St. Louis, MO, Webster University's Community Music School, April 29.

Ross, L. (1977) "The intuitive psychologist and his shortcomings: distortions in the attributional process," in L. Berkowitz, ed., Advances in Experimental Social Psychology, Vol 10 (New York: Academic Press), pp 173-220. 


\section{LINDA M. WOOLF AND MICHAEL R. HULSIZER}

Ross, L., Lepper, M. R. and Hubbard, M. (1975) "Perseverance in self perception and social perception: biased attributional processes in the debriefing paradigm," Journal of Personality and Social Psychology, Vol 32, No 5, pp 880-892.

Roth, K., Bolton, J. R., Slaughter, A. and Wedgwood, R. (1999) Toward an International Criminal Court? Council Policy Initiative (New York: Council on Foreign Relation).

Rummel, R. (1996) Death by Government (New Brunswick, NJ: Transaction).

Sears, D. O. and Kosterman, R. (1994) "Mass media and political persuasion," in S. Shavitt and T. C. Brock, eds, Persuasion: Psychological Insights and Perspectives (Needham Heights, MA: Allyn \& Bacon), pp 251-278.

Simonton, D. K. (1984) Genius, Creativity and Leadership: Historiometric Inquiries (Cambridge, MA: Harvard University Press).

Simonton, D. K. (1987) Why Presidents Succeed: A Political Psychology of Leadership (New Haven, CT: Yale University Press).

Smith, R. W. (1992) “The Armenian genocide: meaning, politics and the future," in R. Hovannisian, ed., The Armenian Genocide: History, Politics, Ethics (New York: St. Martin's Press), pp 1-20.

Smith, R. W. (1999) "State power and genocidal intent: on the uses of genocide in the twentieth century," in L. Chorbajian and G. Shirinian, eds, Studies in Comparative Genocide (New York: St. Martin's Press), p. 10.

Stanton, G. (1998) Eight Stages of Genocide, Genocide Watch, available online at: 〈http://www.genocidewatch. org/8stages.htm $\rangle$ (accessed May 30, 2004).

Staub, E. (1989) The Roots of Evil: The Origins of Genocide and Other Group Violence (New York: Cambridge University Press).

Staub, E. (1999) "Preventing genocide: activating bystanders, helping victims heal, helping groups overcome hostility," in L. Chorbajian and G. Shirinian, eds, Studies in Comparative Genocide (New York: St. Martin's Press), pp 251-160.

Staub, E. (2003) The Psychology of Good and Evil (New York: Cambridge University Press).

Swann, W. B. and Read, S. J. (1981) "Acquiring self-knowledge: the search for feedback that fits," Journal of Personality and Social Psychology, Vol 41, No 6, pp 1119-1128.

Tajfel, H. and Turner, J. C. (1986) "The social identity theory of intergroup behavior," in S. Worchel and W. Austin, eds, The Psychology of Intergroup Relations, 2nd edn (Chicago: Nelson-Hall), pp 7-24.

Trauma Research Education and Training Institute (2004) Healing and Reconciliation in Rwanda Project, available online at: 〈http://www.heal-reconcile-rwanda.org (accessed May 30, 2004).

Turnbaugh, W. A., Jurmain, R., Kilgore, L. and Nelson, H. (2001) Understanding Physical Anthropology and Archaeology, 8th edn (Belmont, CA: Wadsworth), pp 156-161.

Ward, W. C. and Jenkins, H. M. (1965) "The display of information and the judgment of contingency," Canadian Journal of Psychology, Vol 19, No 3, pp 231-241. 